\title{
STAT3 and hypoxia induced proteins - HIF-1alpha, EPO and EPOR in relation with Bax and Bcl-xL in nodal metastases of ductal breast cancers
}

\author{
Andrzej Wincewicz ${ }^{1}$, Mariusz Koda ${ }^{2}$, Mariola Sulkowska ${ }^{2}$, Luiza Kanczuga-Koda ${ }^{1}$, \\ Dominik Wincewicz, Stanislaw Sulkowski ${ }^{2}$
}

Departments of ${ }^{1}$ Medical and ${ }^{2}$ General Pathomorphology, Medical University of Bialystok, Collegium Pathologicum, Medical University of Bialystok, Waszyngtona St 13, 15-269 Bialystok, Poland

\begin{abstract}
STAT3 contributes to increase of EPO expression which is also HIF-1 dependent. EPO receptor activates STAT3. Expressions of STAT3 and hypoxia induced proteins: HIF-1, EPO and EPOR show mutual correlations in primary ductal breast cancers, which suggest co-operation among these proteins. Moreover, EPO-EPOR signaling was reported to mediate cell survival by targeting Bcl-xL in competition with Bax-dependent apoptosis. Our present study was focused on immunohistochemical evaluation of STAT3, HIF-1alpha, EPO and EPOR in relation to apoptosis regulators, Bax and Bcl-xL in 39 metastases of ductal breast cancers to lymph nodes. The proteins were abundantly expressed by cancer cells. HIF-1alpha correlated with EPOR in all and in chemotherapy treated metastases $(r=0.428, p=0.007$ and $r=0.462, p=0.040$, respectively). HIF-1 associated significantly with EPO in chemotherapy spared metastases $(r=0.549, \mathrm{p}=0.015)$ and comparison between those proteins almost reached statistical significance in entire number of metastatic breast cancers $(\mathrm{r}=0.309$, $\mathrm{p}=0.056$ ). Metastases from T2 primary tumors had significantly higher expressions of HIF-1alpha, EPO and EPOR compared to $\mathrm{T} 1$ originating metastases $(\mathrm{p}=0.020, \mathrm{p}=0.028, \mathrm{p}=0.021$, respectively). Bax correlated with EPO and EPOR in all studied nodal metastases $(\mathrm{r}=0.449, \mathrm{p}=0.006$ and $\mathrm{r}=0.421, \mathrm{p}=0.011$, respectively) and so did Bcl-xL with HIF-1alpha $(\mathrm{r}=0.440, \mathrm{p}=0.007)$, EPO and EPOR $(\mathrm{r}=0.383, \mathrm{p}=0.021, \mathrm{r}=0.495, \mathrm{p}=0.002$, respectively). Metastatic breast cancers seem to be areas of intensive signaling by STAT3, HIF-1, EPO and EPOR. Strong Bax and Bcl-xL labeling reflects accelerated cell turnover in nodal metastases. By means of association with Bcl-xL, HIF-1alpha, EPO and EPOR could favor growth of nodal metastases and survival of breast cancers cells.
\end{abstract}

Key words: hypoxia induced proteins, STAT3, nodal metastagenicity, ductal breast cancer

\section{Introduction}

STAT3 (Signal transducer and activator of transcription 3) is an agent that transmits intercellular signals and stimulates gene transcription. STAT3 undergoes activation by phosphorylation of its 705 tyrosine residue. That recruitment is manifested by translocation of STAT3 from cytoplasm to nucleus where this protein acts as nuclear transcription factor. Although it was reported to be overexpressed in cancer and even classified as proto-oncogenic protein, [1] the accumulation of STAT3 can be detected in various non neo-

Correspondence: A. Wincewicz, Department of Medical Pathomorphology, Medical University of Bialystok,

Waszyngtona Str. 13, 15-269 Bialystok, Poland; tel.: (+4885) 7485945, fax.: (+4885) 7485944,

e-mail: homarano@umwb.edu.pl,ruahpolin@yahoo.com plastic conditions of increased cell turnover and their enhanced biosynthesis of various proteins [2,3]. That is why, STAT3 should be viewed as a potent signaling protein whose presence is common in lots of pathological and even physiological conditions [4,5]. Nevertheless, STAT3 is widely explored in various cancers and high expression of its active, phosphorylated form was particularly associated with nodal metastagenicity of breast cancer [6].

Serine and tyrosine phosphorylation of STAT-3 were triggered by EPO (erythropoietin) [7]. Moreover, Tyr432 residue on human erythropoietin receptor (EPOR) was found to activate STAT-3 [8]. EPO is HIF-1 dependent protein [9]. Hypoxia-inducible factor 1 (HIF-1) is a heterodimer that consists of constitutively expressed subunit beta and hypoxia inducible subunit alpha. It is an transcriptional factor that causes transcription of genes that help cell survive the hypox- 
ia injury [9]. Oxygen deficit is a quite common condition in rapidly growing tumors with extensive neoplastic spread into lymph nodes and distant organs. HIF$1 \alpha$ was found to be intensively produced in late stage node positive breast cancers. Overexpression of HIF1alpha was indicator of ominous follow up and significant shortening of survival period [10]. Thus, HIF1alpha target therapy is expected to be advantageous for patients with node positive breast cancers [10]. HIF-1 upregulates transcription of angiogenic genes like erythropoietin (EPO) and vascular endothelial growth factor (VEGF), which induce sprouting of new vessels and in result they increase the risk of metastasis because they boost surface of contact between tumor cells and vasculature [9]. Moreover, HIF-1, EPO and EPOR expressions rise together with development of vascular bed of breast cancers [11-12]. Zhong et al. reported much higher frequency of HIF-1alpha overexpression in breast cancer metastases than primary breast cancers [13]. That fact also suggested HIF-1 is more characteristic for invasive phenotype of breast cancer and more common in metastatic tumors [13]. In addition, EPO-EPOR signaling was reported to mediate cell survival by targeting Bcl-xL (B-cell leukemia/lymphoma extra long protein) and counteract Bax-dependent (BCL-2-associated X protein) apoptosis [14-15].

Expressions of STAT3, HIF-1alpha, EPO and EPOR show mutual correlations in primary invasive ductal breast carcinomas (IDC), which suggests cooperation among these proteins [16]. Encouraged by our results in primary tumors, we sued to evaluate expressions of HIF-1alpha, EPO, EPOR and STAT3 in their nodal metastases. Our study also incorporates correlates of mentioned proteins with Bax and Bcl-xL expression in nodal metastases of ductal breast cancers. Rearrangement of expression of apoptosis regulators is quite intensive in metastatic cancer cell populations which undergo constant and significant renewal. Particularly, increased Bax expression is hallmark of nodal metastagenicity and greater staging and grading of primary breast cancers [17]. In consequence, nodal metastases are sensitive to accelerated apoptosis and subsequent replacement of cell generations due to rapid speed of metastatic growth and lack of sufficient framework of vasculature and connective tissue in lymph nodes. That is why, consistency of nodal metastases is loose and frequently necrotic. In lymph node metastases of breast cancer Bax and Bcl-xL associated very closely with Insulin Receptor Substrate 1 that was reported to correlate positively wit Ki67 labeling as indicator of breast cancer cell growth in primary tumors and nodal metastases [18]. Thus, -in our opinion- HIF-1alpha, EPO, EPOR which are hypoxiainduced rescue proteins for breast cancer cells and their intracellular mediator STAT3 should be compared to expression of Bax and Bcl-xL as well. The aim of our study was to detect and compare STAT3, HIF-1alpha, EPO, EPOR, Bax and Bcl-xL in 39 local lymph nodes with metastases of ductal breast cancer with regard to different characteristics of primary tumors.

\section{Materials and methods}

The 39 local, nodal metastases of ductal breast cancers were surgically removed and evaluated with immunohistochemical staining for STAT3, HIF-1alpha, EPO, EPOR, Bax and Bcl-xL. Some of patients were given preoperative chemotherapy. 3-5 $\mu \mathrm{m}$ thick sections of sampled nodes underwent standard fixation and embedment in paraffin blocks. The slides were dewaxed in xylene and rehydrated through graded alcohols to phosphate buffered saline (PBS). Endogenous peroxidase activity was inhibited in specimens by $2 \%$ hydrogen peroxide. Microwaves were applied for 3 minutes in procedure of EPO antigen retrieval. To eliminate background effects, the specimens were incubated with blocking serum for 1 hour in case of HIF-1alpha, EPO, EPOR and for 90 minutes in case of STAT3. STAT3, EPO, EPOR were labeled with specific antiHIF-1alpha IgG (sc-10790), anti-STAT3 (sc-7179) IgG anti-EPO, H-162, anti-EPOR, C-20 (Santa Cruz Biotechnology, Inc.). Dilution of primary antibodies was 1:500 for STAT3, 1:400 for HIF1alpha, 1:150 for EPO, 1:200 for EPOR, 1:100 for Bax and 1:300 for $\mathrm{Bcl}-\mathrm{xL}$. Incubation took the whole night at $4^{\circ} \mathrm{C}$ except for 2 hours long incubation in EPOR evaluation at room temperature. $\mathrm{Bcl}-\mathrm{xL}$ and Bax were detected with avidin-biotin-peroxidase complex (ABC Staining System; Santa Cruz Biotechnology, Inc., USA) while EnVision (Dako, Denmark) system produced the color reaction in tissues after 7 minutes of exposure to DAB in case of HIF-1alpha evaluation, 6 minutes for EPO, 5 minutes for EPOR and 10 minutes for STAT3 visualization. Sections were counterstained with haematoxylin. In negative controls the primary antibodies were not added. Stained specimens of colorectal cancer were assumed positive controls.

Ethical issues. The studies were performed according to the latest revision of Declaration of Helsinki from 2004 and permitted by the local ethical committee at the Medical University of Bialystok.

Scoring and statistical analysis. Relations in pairs of proteins were analyzed with Spearman's rank correlation test. All the statistical results with $p<0.05$ were assumed to be significant. 3-grade scoring system was used as follows: grade 0 if there was less than $10 \%$ positive cancer cells; grade 1 if positive cancer cells ranged from 10 to $50 \%$; grade 2 if $50 \%$ malignant cells were positive. The immunohistochemical reactions were examined by two pathologists in 10 high power fields of each tumor in light microscopy and the mean rate of tumor positive cells was determined. Chi-square Pearson's was applied to explore statistically significant differences of immunoreactivities of each protein apart in regard to clinico-pathological variables. Grading and staging were not able to be assessed in some of primary tumors in consequence of massive destruction of the cancer cells by chemotherapy. In result the group of tumors with determined $\mathrm{T}$ and $\mathrm{G}$ was smaller and it did not included tumors of chemotherapy administered patients. All patients gave informed consent for inclusion in the study.

\section{Results}

HIF-1alpha and STAT3 expressions were of granular and diffuse pattern of staining in mixed nuclear and cytoplasmic location in cancer cells, while microgranular and disperse immunoreactivities of EPO and EPOR were mostly cytoplasmic with occasional membranous 
Table 1. Analysis of correlations between STAT3, HIF-1alpha, EPO and EPOR expressions in nodal metastases of the breast cancer. Spearman's correlation rank test.

\begin{tabular}{|c|c|c|c|c|c|c|c|}
\hline \multirow{2}{*}{ Cases } & \multirow{2}{*}{$\mathrm{n}^{*}$} & \multicolumn{2}{|c|}{ SlAT3 - IШ'-l $\alpha$} & \multicolumn{2}{|c|}{ SIAT3 - LPO } & \multicolumn{2}{|c|}{ SIAT3 - LPOR } \\
\hline & & $\mathrm{r}$ & $\mathrm{p}$ & $\mathrm{r}$ & $\mathrm{p}$ & $\mathrm{r}$ & $\mathrm{p}$ \\
\hline All & 39 & 0.215 & 0.189 & 0.309 & 0.056 & 0.064 & 0.697 \\
\hline $\mathrm{G} 2$ & 15 & 0.194 & 0.489 & 0.327 & 0.234 & -0.256 & 0.358 \\
\hline G3 & 4 & 0.577 & 0.423 & 0.577 & 0.423 & 0.577 & 0.423 \\
\hline $\mathrm{T} 1$ & 6 & 0.452 & 0.368 & 0.433 & 0.391 & -0.516 & 0.294 \\
\hline $\mathrm{T} 2$ & 13 & 0.104 & 0.735 & - & - & - & - \\
\hline (Ch-) & 19 & 0.297 & 0.217 & 0.327 & 0.171 & -0.068 & 0.784 \\
\hline$(\mathrm{Ch}+)$ & 20 & 0.048 & 0.841 & 0.403 & 0.078 & -0.144 & 0.546 \\
\hline
\end{tabular}

Table 2. Analysis of correlations between HIF-1 $\alpha$, EPO and EPOR expressions in nodal metastases of the breast cancer. Spearman's correlation rank test.

\begin{tabular}{|c|c|c|c|c|c|c|c|}
\hline \multirow{2}{*}{ Cases } & \multirow{2}{*}{$\mathrm{n}^{*}$} & \multicolumn{2}{|c|}{ HIF-1 $\alpha$-EPO } & \multicolumn{2}{c|}{ HIF-1 $\alpha$ - EPOR } & \multicolumn{2}{c|}{ EPO - EPOR } \\
\cline { 3 - 7 } & & $\mathrm{r}$ & $\mathrm{p}$ & $\mathrm{r}$ & $\mathrm{p}$ & $\mathrm{r}$ & $\mathrm{p}$ \\
\hline All & 39 & 0.309 & 0.056 & 0.428 & 0.007 & 0.372 & 0.02 \\
\hline G2 & 15 & 0.423 & 0.117 & 0.186 & 0.508 & -0.105 & 0.711 \\
\hline G3 & 4 & - & - & - & - & - & - \\
\hline T1 & 6 & 0.224 & 0.670 & -0.017 & 0.975 & -0.112 & 0.833 \\
\hline T2 & 13 & - & - & - & - & - & - \\
\hline (Ch-) & 19 & 0.549 & 0.015 & 0.404 & 0.086 & 0.445 & 0.056 \\
\hline (Ch+) & 20 & 0.042 & 0.859 & 0.462 & 0.040 & 0.316 & 0.174 \\
\hline
\end{tabular}

enhancement of staining. Bax and Bcl-xL coalesced in granular fashion in the cytoplasm of breast cancer cells. The proteins were detected in different rates: HIF-1alpha in $87 \%(34 / 39)$ EPO in $97 \%(38 / 39)$, EPOR in $95 \%$ (37/38), STAT3 in 64\% (25/39), Bax 72\% (28/39) and Bcl-xL 92\% (36/39) of all examined nodal metastases.

STAT3 did not correlate with HIF-1alpha and EPOR in ductal breast cancer metastases to lymph nodes. Anyway the trend toward positive correlation was marked in comparison between STAT3 and EPO $(\mathrm{r}=0.309$, $\mathrm{p}=0.056$ ). The severely reduced number of nodal metastases did not apparently allow to draw up reliable comparisons which were conducted in regard to $\mathrm{T}$ and $\mathrm{G}$ status of corresponding primary breast cancers. The limitation resulted from massive destruction of primary tumors by chemotherapy. It disables assessment of grading and staging of primary tumors in regard to expression of most studied proteins in metastases (Table 1).

HIF-1alpha tended to correlate positively with HIF1 depended protein EPO $(r=0.309, p=0.056)$ Furthermore, significant relationship between HIF-1alpha and EPOR was noted in all studied metastases $(\mathrm{r}=0.428$, $\mathrm{p}=0.007) \mathrm{m}$. The statistical significance was also noted in comparison of HIF-1 alpha and EPO in nodal metas- tases, which did not underwent chemotherapy $(\mathrm{r}=0.549, \mathrm{p}=0.015)$. Reversely, chemotherapy treated nodal metastases revealed correlation between HIF1alpha and EPOR ( $\mathrm{r}=0.462, \mathrm{p}=0.040)$ (Table 2).

Bax correlated with EPO and EPOR in all breast cancer patients $(\mathrm{r}=0.449, \mathrm{p}=0.006$ and $\mathrm{r}=0.421$, $\mathrm{p}=0.011$, respectively) and so did Bcl-xL with HIF1alpha $(r=0.440, p=0.007)$, EPO and EPOR, $(r=0.383$, $\mathrm{p}=0.021, \mathrm{r}=0.495, \mathrm{p}=0.002$, respectively). In opposition, HIF-1alpha faled to significantly associate with Bax in all metastatic tumors and STAT3 didn't correlate with Bcl-xL and either Bax in all nodal metastases of colorectal cancers (Table 3 and 4).

Interestingly, metastases, which derived from $\mathrm{T} 2$ primary tumors, had significantly higher expression of hypoxia induced proteins like HIF-1alpha, EPO and EPOR than $\mathrm{T} 1$ originating metastases $(\mathrm{p}=0.020$, $\mathrm{p}=0.028, \mathrm{p}=0.021$, respectively). Immunoreactivity to STAT3 did not change in nodal metastases due to varied staging of corresponding primary tumors. Chemotherapy tended to reduce expression of STAT3 in nodal metastases of breast cancer $(p=0.070)$ without statistical significance, but it did not effect statistics at all in case of HIF-1alpha, EPO and EPOR (Table 5). 
Table 3. Correlations of Bax with STAT3, HIF-1alpha, EPO and EPOR expressions in nodal metastases of the breast cancer. Spearman's correlation rank test.

\begin{tabular}{|c|c|c|c|c|c|c|c|c|}
\hline \multirow{2}{*}{ Cases } & \multicolumn{2}{|c|}{ Bax - STAT3 } & \multicolumn{2}{c|}{ Bax - HIF-1 $\alpha$} & \multicolumn{2}{c|}{ Bax - FPO } & \multicolumn{2}{c|}{ Bax - FPOR } \\
\cline { 2 - 9 } & $\mathrm{r}$ & $\mathrm{p}$ & $\mathrm{r}$ & $\mathrm{p}$ & $\mathrm{r}$ & $\mathrm{p}$ & $\mathrm{r}$ & $\mathrm{p}$ \\
\hline All & 0.040 & 0.818 & 0.285 & 0.092 & 0.449 & 0.006 & 0.421 & 0.011 \\
\hline G2 & -0.058 & 0.850 & 0.163 & 0.595 & 0.384 & 0.195 & 0.384 & 0.195 \\
\hline G3 & 0.943 & 0.057 & 0.816 & 0.184 & 0.816 & 0.184 & 0.816 & 0.184 \\
\hline $\mathrm{T} 1$ & 0.354 & 0.559 & 0.177 & 0.776 & 0.645 & 0.239 & 0.645 & 0.239 \\
\hline $\mathrm{I} 2$ & -0.174 & 0.589 & -0.067 & 0.837 & - & - & - & - \\
\hline$(\mathrm{Ch}-)$ & 0.197 & 0.450 & 0.251 & 0.331 & 0.458 & 0.064 & 0.458 & 0.064 \\
\hline$(\mathrm{Ch}+)$ & -0.076 & 0.757 & 0.329 & 0.17 & 0.443 & 0.058 & 0.396 & 0.093 \\
\hline
\end{tabular}

Table 4. Correlations of Bcl-xL with STAT3, HIF-1alpha, EPO and EPOR expressions in nodal metastases of the breast cancer. Spearman's correlation rank test.

\begin{tabular}{|c|c|c|c|c|c|c|c|c|}
\hline \multirow{2}{*}{ Cases } & \multicolumn{2}{|c|}{ Bcl-xL - SlAT3 } & \multicolumn{2}{|c|}{ Bcl-xL - IШl- $1 \alpha$} & \multicolumn{2}{|c|}{$\mathrm{Bcl}-\mathrm{xL}-\mathrm{LPO}$} & \multicolumn{2}{|c|}{ Bcl-xL - LPOOR } \\
\hline & $r$ & $\mathrm{p}$ & $r$ & $\mathrm{p}$ & $\mathrm{r}$ & $\mathrm{p}$ & $\mathrm{r}$ & $\mathrm{p}$ \\
\hline All & 0.192 & 0.263 & 0.440 & 0.007 & 0.383 & 0.021 & 0.495 & 0.002 \\
\hline G2 & 0.134 & 0.663 & 0.475 & 0.101 & 0.215 & 0.481 & 0.215 & 0.481 \\
\hline G3 & 0.577 & 0.423 & - & - & - & - & - & - \\
\hline $\mathrm{T} 1$ & 0.745 & 0.148 & 0.559 & 0.327 & 0.408 & 0.495 & 0.408 & 0.495 \\
\hline $\mathrm{T} 2$ & 0.083 & 0.798 & 0.469 & 0.124 & - & - & - & - \\
\hline (Ch-) & 0.386 & 0.126 & 0.572 & 0.016 & 0.371 & 0.142 & 0.371 & 0.142 \\
\hline$(\mathrm{Ch}+)$ & -0.021 & 0.931 & 0.300 & 0.212 & 0.414 & 0.078 & 0.596 & 0.007 \\
\hline
\end{tabular}

Table 5. Statistical differences in expression of STAT3, HIF1alpha, EPO and EPOR in nodal metastases derived from primary ductal breast cancers of different variables as histological differentiation $\mathrm{G}$, primary tumor size $\mathrm{T}$, and presence or absence of chemotherapy. Pearson's Chi-square test.

\begin{tabular}{|c|c|c|c|c|c|}
\hline \multirow{2}{*}{ Cases } & \multirow{2}{*}{$\mathrm{n}^{*}$} & STAT3 & $\begin{array}{l}\text { ШШ'- } \\
\text { 1alpha }\end{array}$ & EPO & EPOR \\
\hline & & $\mathrm{p}$ & $\mathrm{p}$ & $\mathrm{p}$ & $\mathrm{p}$ \\
\hline G2 & 15 & \multirow{2}{*}{0.405} & \multirow{2}{*}{0.622} & \multirow{2}{*}{0.288} & \multirow{2}{*}{0.515} \\
\hline G3 & 4 & & & & \\
\hline $\mathrm{T} 1$ & 6 & \multirow{2}{*}{0.895} & \multirow{2}{*}{0.020} & \multirow{2}{*}{0.028} & \multirow{2}{*}{0.021} \\
\hline $\mathrm{T} 2$ & 13 & & & & \\
\hline (Ch-) & 19 & \multirow{2}{*}{0.070} & \multirow{2}{*}{0.103} & \multirow{2}{*}{0.547} & \multirow{2}{*}{0.775} \\
\hline$(\mathrm{Ch}+)$ & 20 & & & & \\
\hline
\end{tabular}

$\mathrm{n}$ - number of cases, G2 - moderately differentiated, G3 - poorly differentiated, T- tumor size, T1 tumor $2 \mathrm{~cm}$ or less in greatest dimension, T2tumor more than $2 \mathrm{~cm}$ but not more than $5 \mathrm{~cm}$ in greatest dimension. $(\mathrm{Ch}+)$ - chemotherapy treaded cases, (Ch-) - chemotherapy spared cases.

*The amounts of investigated cancer metastases different and were limited because $\mathrm{G}$ and $\mathrm{T}$ were not assessed in certain primary tumors because of cellular damage due to chemotherapy, that appeared to spare more nodal metastases than primary foci of cancers.

\section{Discussion}

Nodal metastases of ductal breast cancer seem to be the field of intensive signaling with participation of STAT3, HIF-1alpha, EPO and EPOR molecules. The relations between these proteins are highlighted by positive correlations or trends toward them in our work. Tight regulation between HIF-1alpha and its downstream proteins is proved by correlation between HIF-1alpha and EPOR and the trend toward the significance between HIF-1alpha and EPO in all nodal metastases of ductal breast cancer. Considering the silencing role of chemotherapy, only expression of STAT3 tended to be reduced in chemotherapy treated nodal metastases of breast cancer, but this trend was still below level of statistical significance in our study (Table 5). Although statistically significant differences did not occur in comparison of each protein alone in regard to variable staging in primary breast cancers [16], expressions of HIF-1alpha, EPO and EPOR were markedly increased in metastases which originated from larger T2 primary tumors in our present study. It seems that cancer cells that came from larger primary 

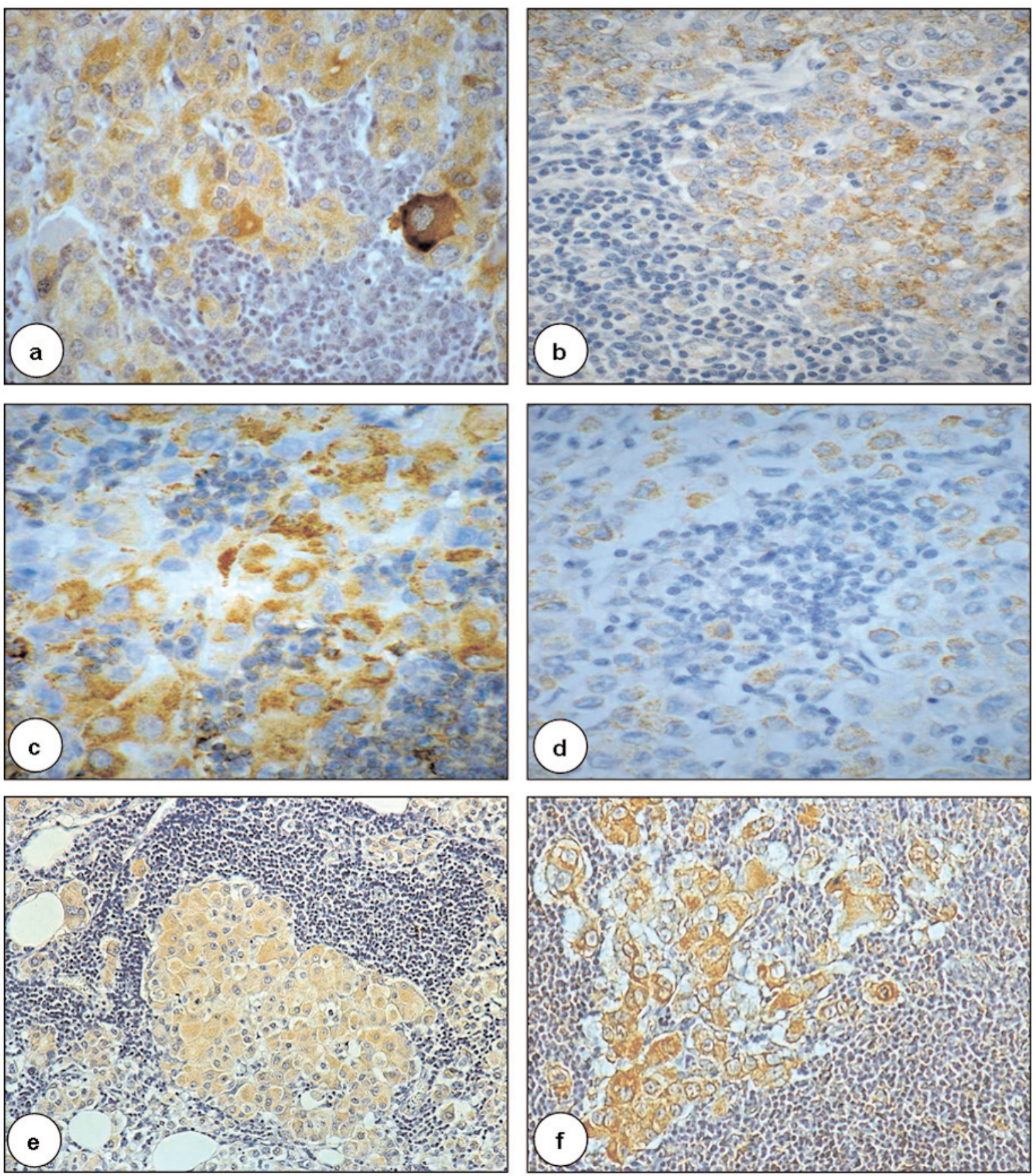

Fig. 1. Immunohistochemistry showing expression of STAT3 (Fig. 1a), HIF-1alpha (Fig. 1b), EPO (Fig. 1c,), EPOR (Fig 1d), Bax (Fig 1e) and Bcl-xL (Fig 1f) in nodal metastases of ductal breast cancer. (a). Finely granular condensing cytoplasmic staining showing STAT3 expression in metastatic cancer cells. Lymph node metastasis (original magnification $\times 200$ ). (b). Cytoplasmic, coarse granules and intense perinuclear rim positive for HIF-1alpha. Metastatic breast cancer cells encircling necrosis in the fashion of comedocarcinoma at periphery of a lymph node (original magnification $\times 200$ Fig. (c). Metastatic breast cancer show peripheral membrane - associated cytoplasmic immunostain for EPO in lymph node metastasis of breast cancer (original magnification $\times 400$ ). (d). Clumped cytoplasmic immunoreactivity to EPOR in cytoplasm of breast cancer cells. Lymph node metastasis (original magnification $\times 200$ ). (e). Anti-Bax staining evenly distributed in manner of fine granules in cytoplasm of breast cancer cells. Lymph node metastasis (original magnification $\times$ 100). (f). Granular focally increased anti-Bcl-xL labeling in cytoplasm of breast cancer cells. Lymph node metastasis (original magnification $\times 200)$.

cancers are better adapted to survive hypoxic injury as they overexpress cytoprotective proteins like HIF1alpha, EPO and EPOR in greater extend than nodal metastases from smaller T1 tumors.
HIF-1 exerts an impact on cell survival by relations with apoptosis regulators in colorectal cancers [19]. In our study, HIF-1alpha was confirmed to promote survival by positive correlation with $\mathrm{Bcl}-\mathrm{xL}$ and simulta- 
neous loss of association with Bax. Lack of EPO, which signals by its receptor EPOR, was reported to decrease Bcl-xL but not to affect Bax expression in HCD-57, a murine erythroid progenitor cell line [20]. Similarly, EPO and EPOR could effect turnover of breast cancer cells in nodal metastases of our present study because this ligand and its receptor correlated with both antiapoptotic Bcl-xL and proapoptotic Bax. Particularly, linkage of Bax with EPO and EPOR could point at the possibility that EPO and EPOR might simultaneously be expressed to counteract cell death in malignant tumors with high expression of Bax and their subsequent higher susceptibility to apoptosis.

Lee et al. proved STAT3 involvement in regulation of Bax and Bcl-xL expression in cell lines of head and neck squamous cell carcinoma (HNSCC). This reported regulatory function depended on P53 status. Namely, decrease of wild-type P53 was accompanied with activation of NF-kappaB, STAT3 and Bcl-xL. This effect was less apparent in HNSCC expressing mutated type of P53. Reintroduction of wild type P53 downregulated STAT3 and Bcl-xL to increase Bax expression [21]. On the basis of such experiment promotion of cell survival was attributed to properties of STAT3 [21]. Appliance of STAT3 inhibitors (such as AG490 or WP1066) led to suppression of growth and induction of apoptosis in malignant gliomas [22]. Abrogation of STAT3 function resulted in increase of Bax expression and decrease of Bcl-xL [20]. In opposition, our present investigations were failed to reflect any impact of STAT3 on Bax and Bcl-xL.

To sum up, STAT3, HIF-1alpha, EPO and EPOR appear to be associated with one another in studies over metastases of ductal breast cancer to local lymph nodes. High rates of Bax and Bcl-xL positive metastases reflect accelerated cell turnover in nodal location of breast cancers. HIF-1alpha, EPO and EPOR could favor growth of nodal metastases and survival of breast cancers cells by means of association with Bcl$\mathrm{xL}$ and the fact that expressions of HIF-1 $\alpha$, EPO and EPOR were markedly increased in metastases which originated from larger T2 primary tumors.

Acknowledgements: Andrzej Wincewicz thanks the Foundation for Polish Science for granting him a START scholarship, which supported him in this study.

\section{References}

[ 1] Ling X and Arlinghaus RB. Knockdown of STAT3 expression by RNA interference inhibits the induction of breast tumors in immunocompetent mice. Cancer Res. 2005;65:2532-6.

[2] Sawa S, Kamimura D, Jin GH et al. Autoimmune arthritis associated with mutated interleukin (IL)-6 receptor gp130 is driven by STAT3/IL-7-dependent homeostatic proliferation of CD4+ T cells. J Exp Med. 2006;203:1459-70.

[3] Murray PJ. STAT3-mediated anti-inflammatory signalling. Biochem Soc Trans. 2006;34:1028-31.
[ 4] Trenerry MK, Carey KA, Ward AC et al. STAT3 signaling is activated in human skeletal muscle following acute resistance exercise. J Appl Physiol. 2007;102:1483-9.

[ 5] Watanabe S, Mu W, Kahn A et al. Role of JAK/STAT pathway in IL-6-induced activation of vascular smooth muscle cells. Am J Nephrol. 2004;24:387-92.

[6] Hsieh FC, Cheng G and Lin J. Evaluation of potential Stat3regulated genes in human breast cancer. Biochem. Biophys Res Commun. 2005;335:292-9.

[ 7] Haq R, Halupa A, Beattie BK et al. Regulation of erythropoietin-induced STAT serine phosphorylation by distinct mitogen-activated protein kinases. J Biol Chem. 2002;277:17359-66.

[ 8] Kirito K, Nakajima K, Watanabe T et al. Identification of the human erythropoietin receptor region required for Stat1 and Stat3 activation. Blood. 2002,99:102-10.

[ 9] Wang GL and Semenza GL. General involvement of hypoxia-inducible factor 1 in transcriptional response to hypoxia. Proc Natl Acad Sci U S A. 1993;90:4304-8.

[10] Schindl M, Schoppmann SF, Samonigg H et al. Overexpression of hypoxia-inducible factor 1alpha is associated with an unfavorable prognosis in lymph node-positive breast cancer. Clin Cancer Res. 2002;8:1831-7.

[11] Bos R, Zhong H, Hanrahan CF et al. Levels of hypoxiainducible factor-1 alpha during breast carcinogenesis. $J$ Natl Cancer Inst. 2001;93:309-14.

[12] Acs G, Acs P, Beckwith SM et al. Erythropoietin and erythropoietin receptor expression in human cancer. Cancer Res. 2001;61:3561-5.

[13] Zhong H, De Marzo AM, Laughner E et al. Overexpression of hypoxia-inducible factor 1alpha in common human cancers and their metastases. Cancer Res. 1999;59:5830-5.

[14] Dolznig H, Habermann B, Stangl K et al. Apoptosis protection by the Epo target $\mathrm{Bcl}-\mathrm{X}(\mathrm{L})$ allows factor-independent differentiation of primary erythroblasts. Curr Biol. 2002;12: 1076-85.

[15] Kumral A, Genc S, Ozer E et al. Erythropoietin downregulates bax and DP5 proapoptotic gene expression in neonatal hypoxic-ischemic brain injury. Biol Neonate. 2006;89:205-10.

[16] Wincewicz, A, Sulkowska M, Koda M et al. STAT3, HIF-1 $\alpha$, EPO and EPOR - signaling proteins in human primary ductal breast cancers. Folia Histochem Cytobiol. 2007;45:81-86.

[17] Koda M, Przystupa W, Jarzabek K et al. Expression of insulin-like growth factor-I receptor, estrogen receptor alpha, Bcl-2 and Bax proteins in human breast cancer. Oncol Rep. 2005; 14: 93-8.

[18] Koda M, Sulkowska M, Kanczuga-Koda L et al. Expression of the Insulin Receptor Substrate 1 in primary tumors and lymph node metastases in breast cancer: correlations with Bcl-xL and Bax proteins. Neoplasma. 2005;52:361-3.

[19] Wincewicz A, Sulkowska M, Koda M et al. Cumulative expression of HIF-1-alpha, Bax, Bcl-xL and P53 in human colorectal cancer. Pathology. 2007;39:334-8.

[20] Silva M, Grillot D, Benito A et al. Erythropoietin can promote erythroid progenitor survival by repressing apoptosis through Bcl-XL and Bcl-2. Blood. 1996;88:1576-82.

[21] Lee TL, Yeh J, Friedman J et al. A signal network involving coactivated NF-kappaB and STAT3 and altered p53 modulates BAX/BCL-XL expression and promotes cell survival of head and neck squamous cell carcinomas. Int J Cancer. 2008; 122:1987-98.

[22] Iwamaru A, Szymanski S, Iwado E et al. A novel inhibitor of the STAT3 pathway induces apoptosis in malignant glioma cells both in vitro and in vivo. Oncogene. 2007;26:2435-44.

Submitted: 2 March, 2009 Accepted after reviews: 25 July, 2009 